\title{
Clorhexidine as a factor that promotes peritoneal adhesions in rats with induced peritonitis ${ }^{1}$
}

\author{
Paulo Roberto Rodrigues Bicalho ${ }^{\mathrm{I}}$, Claudio Alvarenga Campos Mayrink", Fernando Fernandes", Daniel Gomes de Alvarenga ${ }^{\text {III }}$, \\ Tarcizo Afonso Nunesiv, Fabíola Alves dos Reis ${ }^{\mathrm{v}}$, Ivana Duval Araújo ${ }^{\mathrm{VI}}$
}

\begin{abstract}
${ }^{I}$ Master, Fellow PhD degree, Postgraduate Program in Surgery, Medical School, Federal University of Minas Gerais (UFMG), Belo Horizonte-MG, Brazil. Acquisition and interpretation of data, technical procedures, statistical analysis, manuscript writing, critical revision.

IIMD, Resident, Medical School, UFMG, Belo Horizonte-MG, Brazil. Acquisition and interpretation of data, technical procedures.

IIIMaster. Assistant Professor, Division of Pathology, School of Health Sciences, Vale do Rio Doce University (UNIVALE), Governador Valadares-MG, Brazil. Macroscopic and histopathological examinations, interpretation of data, critical revision.

${ }^{\text {IV }}$ PDD, Full Professor, Department of Surgery, Medical School, UFMG, Belo Horizonte-MG, Brazil. Manuscript writing, critical revision.

${ }^{\mathrm{v}} \mathrm{PhD}$, Associate Professor, Division of Human Anatomy, School of Health Sciences, UNIVALE, Governador Valadares-MG, Brazil. Statistical analysis, manuscript writing, critical revision.

${ }^{\mathrm{V}} \mathrm{PhD}$, Associate Professor, Department of Surgery, Medical School, UFMG, Belo Horizonte-MG, Brazil. Intellectual and scientific content of the study, design the protocol, interpretation of data, manuscript writing, critical revision.
\end{abstract}

\section{ABSTRACT}

PURPOSE: To investigate the effects of chlorhexidine on the formation of adhesions and dilation of the colon at the oral end of anastomosis in the presence of peritonitis.

METHODS: Peritonitis was induced in male Wistar rats by cecal ligation and puncture (CLP). Abdominal cavities were irrigated with tepid solutions containing $0.9 \%$ saline (SAL group; $\mathrm{n}=8$ ) or $0.05 \%$ chlorhexidine (CHD group; $\mathrm{n}=8$ ), after which colon anastomoses were performed. Control rats $(n=8)$ were submitted to colon anastomoses but not to CLP. Animals were euthanised seven days after surgery and the incidence of adhesions, the degree of dilation of colon loops and an index were calculated to determine variables correlation.

RESULTS: No animals exhibited macroscopic signs of residual peritonitis or abdominal abscesses. Adhesions were observed in $75 \%$ of control and $100 \%$ of SAL and CHD animals. Dilation of intestinal loops at the oral end of anastomosis was observed in control (50\%), SAL (57.2\%) and CHD (66.7\%) animals. The calculated index was 1.25 in group A; 1.86 in group B; and 2.0 group C.

CONCLUSION: Chlorhexidine promoted stronger adhesions and a greater dilatation of colonic loops than control group.

Key words: Peritonitis. Chlorhexidine. Tissue Adhesions. Colon. Models, Animal. Rats. 


\section{Introduction}

The formation of peritoneal adhesions represents part of the anatomical and functional repair processes that occur following a chemical, physical or biological injury ${ }^{1,2}$. Such adhesions are produced by the deposition of fibrin during the initial stages of inflammation of the abdominal cavity when the organism is trying to restore homeostasis ${ }^{3,4}$. Although this type of complication is intrinsic to surgical procedures, it may also occur as a consequence of other inflammatory processes and can evolve into more severe conditions including intestinal obstruction and chronic abdominal pain. The presence of peritoneal adhesions constitutes a risk factor for infertility and can give rise to complications in later surgery by increasing the complexity and duration of the procedure ${ }^{2,5,6}$.

The quantification and classification of adhesions is very important for the standardization and comparison of surgical procedures, as well as in the validation of experimental results. Typically adhesions are categorized according to a subjective system that encompasses a grading severity score $^{7}$, and such methods are very valuable in helping surgeons to recognize critical situations and to adopt more effective measures ${ }^{8}$. Most published indexes are based on the number of fibrotic strands formed, the extension of the contact area between the structures and the strength required to separate them ${ }^{3,9-14}$.

Despite the advances in surgical procedures, intensive care, and antimicrobials, together with a better understanding of the physiopathology of healing and repair, the prognosis for patients with severe abdominal sepsis is poor, particularly for those in need of re-operation ${ }^{15}$, the final outcome depends on the complex interaction between cells and anti- and pro-inflammatory substances $^{1}$. It is believed that control of bacterial contamination with reduction on local and systemic inflammatory reaction, can give rise to a reduction in the deposition of fibrin and the formation of adhesions. Hence, the investigation of agents or procedures that interfere with these processes is very valuable in improving the success of abdominal surgeries.

To improve the system of evaluation of peritoneal adhesions the existence of correlation of formed and the strength of the structure's detachment, a subjective measure, with the dilation of colon loops at the oral end of the anastomosis line comparing it with the same loops the aboral end, a numerical variable was investigate. During the investigation of the impact of peritoneal chlorhexidine irrigation in the prevention of postoperative complications whose objective was to assess the the macroscopic aspects of abdominal healing in rats submitted to peritonitis by cecal ligation and puncture (CLP).

\section{Methods}

Project approved by the Ethics Committee on Animal Experimentation of UFMG (protocol 38/2007). Twelve weekold male Wistar rats were randomly distributed into three groups, namely, a control group $(\mathrm{n}=8)$, a saline-treatment group (SAL; $\mathrm{n}=8$ ), and a chlorhexidine-treatment group (CHD; $\mathrm{n}=8)$. The animals were maintained at room temperature under a light-dark cycle of $12 \mathrm{~h}$ in cages lined with non-toxic wood shavings. Water and ration were offered ad libitum in the amounts recommended for the species at that age.

\section{Surgical procedure}

All animals were anesthetised with an intramuscular injection of ketamine $(40 \mathrm{mg} / \mathrm{kg}$, Cristália Produtos Químicos e Farmacêuticos, Itapira, SP, Brazil) together with xylazine $(8 \mathrm{mg} /$ $\mathrm{kg}$; Schering-Plough, Cotia, SP, Brazil). Animals of the SAL and CHD groups were placed on cork mats and peritonitis was induced by the means of cecal ligation and puncture (CLP) according to the standard procedure ${ }^{16}$. A single-layer closure of the abdominal wall was subsequently performed, and the animals were allowed to recover for two hours prior to being re-anaesthetised. With the aim to treat infection, abdominal cavities were cleaned with sterile muslin dampened in $0.9 \%$ saline solution and irrigated $(4 \times 5 \mathrm{~mL})$ with either $0.9 \%$ saline solution or $0.05 \%$ chlorhexidine solution warmed to $37^{\circ} \mathrm{C}$. Following this treatment, the ascending colon was identified, sectioned around $75 \%$ of the circumference at the antimesenteric border and anastomoses were performed by manual extramucosal single-layer suture. On average six separate stitches were applied using polyglactin 910 strands. Control animals were submitted to colon anastomoses but without CLP. All animals received the antibiotic ceftriaxone $(30 \mathrm{mg} / \mathrm{kg}$; Rocephin, Roche, Jacarepaguá, Brazil; $30 \mathrm{mg} / \mathrm{kg}$ ), administered via intramuscular injection, for three consecutive days after surgery, and euthanasia was performed seven days after surgery by administration of a super-dose of ketamine $(120 \mathrm{mg} / \mathrm{kg}$, Cristália Produtos Químicos e Farmacêuticos, Itapira, SP, Brazil).

\section{Macroscopic assessment of treatments}

Macroscopic alterations along the line of the colonic anastomoses were identified and classified according to: (i) the presence, number and type of anastomotic adhesions (Table 1) and the organs involved, (ii) the presence of perianastomotic abscesses, (iii) the degree of peritonitis (localised or widespread, including 
the number of abdominal quadrants involved), (iv) the number of fistulas (open or clogged) in the peritoneum or organs, and (v) the dilation of colon loops at the oral end of the anastomosis line (Table 1; the aboral end of anastomosis served as control).

TABLE 1 - Classification of adhesions and dilations of intestinal loops at the oral end of the anastomosis.

\begin{tabular}{cc}
\hline Category & Characteristics \\
\hline Adhesions & $\begin{array}{c}\text { loosely attached, easily releasable by } \\
\text { manipulation }\end{array}$ \\
Grade I & $\begin{array}{c}\text { structures } \\
\text { tightly attached, easily releasable by traction of } \\
\text { Grade II }\end{array}$ \\
Grade III & $\begin{array}{c}\text { very tightly attached, not easily releasable by } \\
\text { traction of structures }\end{array}$ \\
\hline Dilations & $\begin{array}{c}\text { slight dilation, } 1 \times \text { the normal calibre; } \\
\text { Grade I } \\
\text { Grade II }\end{array}$ \\
Grade III & $\begin{array}{c}\text { considerable dilation, } 2 \times \text { the normal calibre; } \\
\text { calibre. }\end{array}$ \\
\hline
\end{tabular}

After measuring the degree of adhesions and swelling index calculated for each group, variables were compared. This index represents the sum of the product of the number of animals affected by the intensity observed divided by the number of animals of that group. Between-group comparisons were performed using the $\chi^{2}$ test with the Yates correction, and significant differences were established at $\rho<0.05$.

\section{Results}

The post-operative survival rates within the control, SAL and CHD groups were 100; 87.5; and 75\%, respectively, but the difference between the treatment groups was not significant ( $\rho=0.27$ ). Following seven days of surgery, no surviving animals exhibited macroscopic signs of residual peritonitis or perianastomotic abdominal abscesses. There were no statistical differences between the mean numbers of adhesions present in animals of the control group (mean $1.6 \pm 0.9$ ) and those of the SAL group (mean $1.1 \pm 0.4$ ) or of the CHD group (mean $1.8 \pm$ 0.8). As may be seen from Table 2, two individuals of the control group exhibited no adhesions, but the remaining animals presented adhesions of grades I, II or III, with $50 \%$ being classified as grade I.
TABLE 2 - Adhesions and dilations in intestinal loops at the oral end of the anastomosis presented by animals of the control, SAL (treated with $0.9 \%$ saline solution) and CHD (treated with $0.05 \%$ chlorhexidine solution) groups.

\begin{tabular}{|c|c|c|c|}
\hline & $\begin{array}{c}\text { Control } \\
n=8\end{array}$ & $\begin{array}{l}\text { SAL } \\
n=7\end{array}$ & $\begin{array}{l}\text { CHD } \\
n=6\end{array}$ \\
\hline $\begin{array}{l}\text { Number }(\%) \text { of animals } \\
\text { presenting adhesions }\end{array}$ & $6(75)$ & 7 (100) & $6(100)$ \\
\hline $\begin{array}{l}\text { Severity of adhesions } \\
\text { observed - Grade I }\end{array}$ & $3(50)^{*}$ & $1(14.3)^{*}$ & $0^{*}$ \\
\hline - Grade II & $2(33.3)$ & $6(85.7)$ & $6(100)$ \\
\hline - Grade III & $1(16.7)$ & 0 & 0 \\
\hline $\begin{array}{l}\text { Number }(\%) \text { of animals } \\
\text { presenting dilation of } \\
\text { intestinal loops }\end{array}$ & $4(50)$ & $4(57.2)$ & $4(66.7)$ \\
\hline $\begin{array}{l}\text { Severity of dilations } \\
\text { observed - Grade I }\end{array}$ & $4(100)^{*}$ & $2(50)$ & $0^{*}$ \\
\hline - Grade II & 0 & $1(25)$ & $2(50)$ \\
\hline - Grade III & 0 & $1(25)$ & $2(50)$ \\
\hline
\end{tabular}

* Within a row, the symbol * indicates significant differences between the values presented $(\rho=0.04)$

Indeed, the incidence of grade I adhesions in the control group was significantly greater $(\rho=0.04)$ than in either the SAL or the CHD groups. No grade III adhesions were observed in animals of the SAL and CHD groups, although $85.7 \%$ of individuals of the SAL group and $100 \%$ of those of the CHD group presented grade II adhesions. Within the control group, the most frequent organs adhered to the anastomosis were the small intestine and omentum (33.3\% of animals), the small intestine and cecum $(16.7 \%$ of animals) and the small intestine (16.7\% of animals) and omentum (16.7\% of animals). In the SAL group, adhesions involved the small intestine $(57.1 \%$ of animals) and the omentum $(42.9 \%$ of animals), whereas adhesions observed in the CHD group involved the small intestine $(33.3 \%$ of animals), the small intestine and cecum (33.3\%), the omentum (16.7\% of animals) and the small intestine and omentum (16.7\% - Figure 1). 


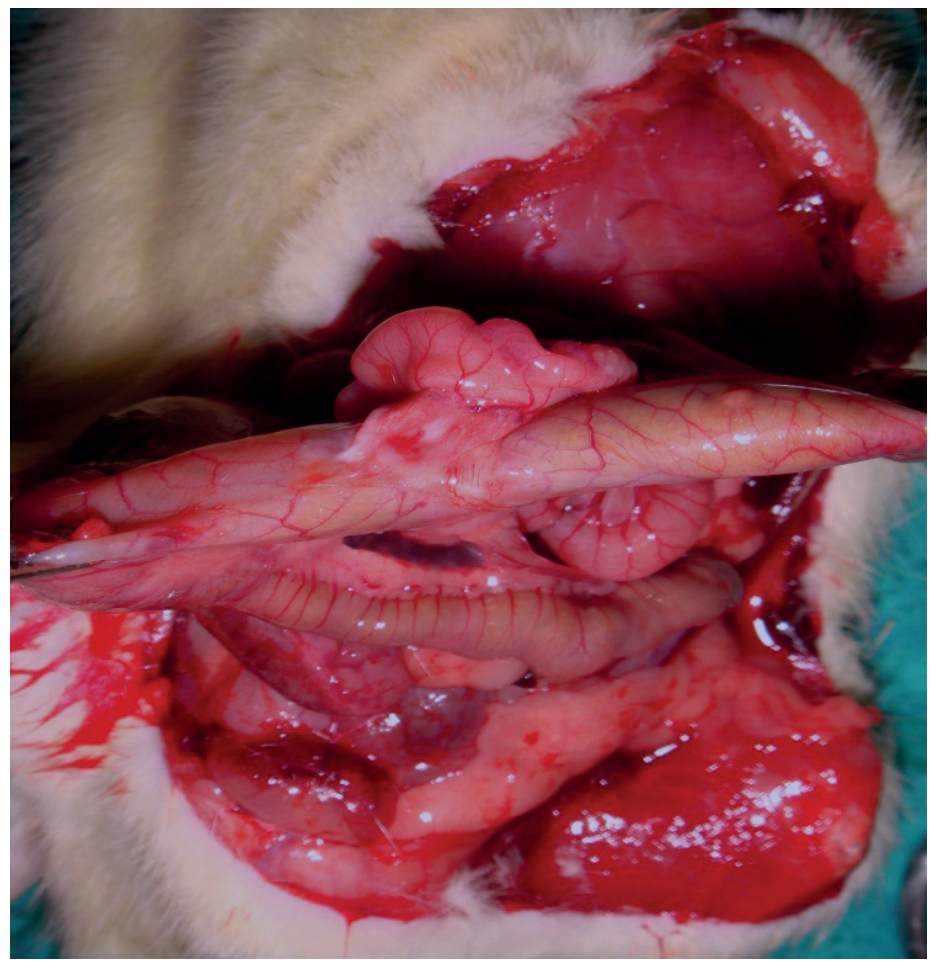

FIGURE 1 - Macroscopic aspects of the abdominal cavity of rats seven days after colon ligation and puncture. The area had been treated with $0.05 \%$ chlorhexidine solution for the purpose of avoiding infection. The cross indicates colon anastomosis, whereas the arrows point to adhesions between the small intestine and anastomosis. No colon dilation can be observed at the oral end of the anastomosis.

The presence of covered fistulas was observed in only one animal each of the control (12.3\%) and SAL (14.3\%) groups, with no significant difference between the two groups. Half of the control animals exhibited dilations in the intestinal loops at the oral end of the anastomosis, all of which were classified as grade I (Table 2).

In the SAL group, four animals presented dilations of grades I, II or III, with $50 \%$ being classified as grade I, whilst within the CHD group, four animals exhibited dilations, half of which were classified as grade II and half as grade III.

The index of the intensities of adhesions perianastomotic was 1.25 in group A; 1.86 in group B; and 2.0 in group C 2.0 and the index of dilatation of loops at the oral end of anastomosis was 0.50 in group $\mathrm{A} ; 1.0$ in group $\mathrm{B}$; and 1.67 in group $\mathrm{C}$ with positive relationship between them (Figure 2).

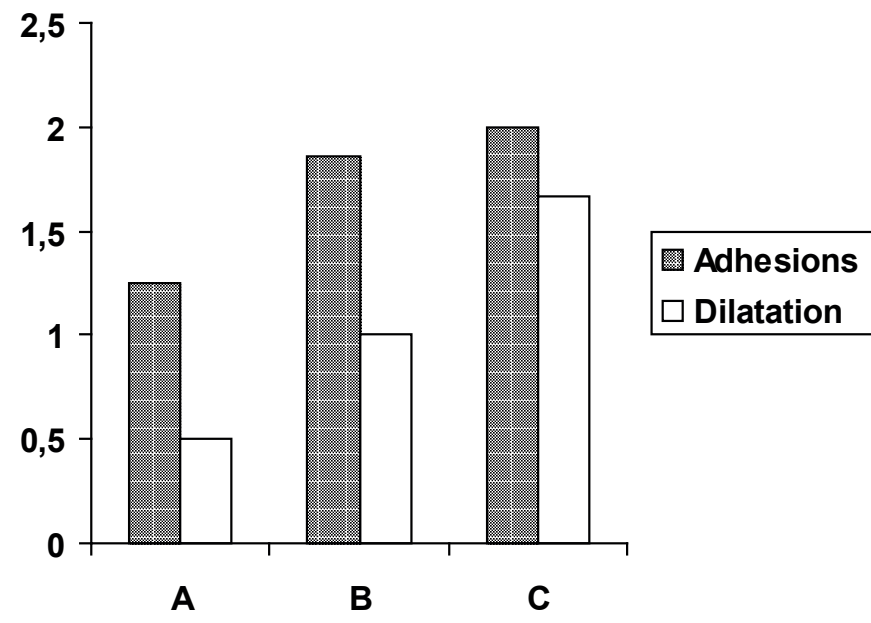

FIGURE 2 - Relationship of the intensities of the index of adhesions perianastomotic with dilatation of loops at the oral end of anastomosis.

\section{Discussion}

The risk of post-surgical complications caused by the presence of intra-abdominal adhesions is approximately $20 \%$ in reoperations via laparotomy, but can increase up to $100 \%$ depending on the patient and the procedure employed ${ }^{6}$. Similar problems also occur as a consequence of trauma, intra-abdominal sepsis, radiation, endometriosis and pelvic inflammatory disorder ${ }^{17}$.

Considerable effort has been made to investigate the origin of adhesions and to prevent such complications after surgical procedures. In order to minimise the formation of adhesions, good surgical practice requires the delicate manipulation of intestinal loops, careful haemostasis, and the preclusion of contact between the serous surfaces and irritating fluids (i.e. gastric enteric secretions) and powder from surgical gloves ${ }^{17}$. Additional surgical approaches have been explored in an attempt to prevent adhesions, and these include irrigation with crystalloid solution, high molecular weight dextran or non-steroidal anti-inflammatory drugs. However, these techniques have not proven to be completely effective in the clinical domain and have not been definitively incorporated into surgical practice ${ }^{18}$.

In the present study, irrigation of the abdominal cavity with chlorhexidine was ineffective in the prevention of adhesions, since the frequencies of adhesions exhibited by animals of the CHD, SAL and control groups were not significantly different. This finding is in agreement with that reported by Sortini et al. ${ }^{19}$, but differs from results obtained by Maleckas et al. ${ }^{20}$. A bias may have occurred in this study related with a subjective measure, although, there was positive correlation between the subjective criterion: the intensity of adhesions and objective criterion: dilatation of 
the loops. Moreover, other methods for studying these adhesions also come up against this bias, since all are examiner-dependent ${ }^{2}$. As noted in rodents inflammatory response more exuberant and effective, the results seen in this study and others may be more related to the experimental model used than the procedure tested. However, the adhesions observed in animals of the CHD group comprised more organised tissue than that found in the control and SAL groups. Hence, in this way, the present results are similar to those obtained by Malekas et al. ${ }^{20}$.

There was a positive relationship between the dilatation of colon loops, a numeric variable, and the intensity of adhesions, a subjective measure. Considering the results presented and the wound healing response of rodents is supposed to promote stronger adhesions and greater reduction in the intestinal lumen, therefore, greater dilation of the loops, however, further studies are required to take the dilatation of the loops at oral end of anastomosis as a variable comparison of the effectiveness of prevention measures intra-abdominal adhesions.

\section{Conclusion}

Chlorhexidine promoted stronger adhesions and a greater dilatation of colonic loops than control group and there was positive relationship between the degree of adhesions and the intensity of the dilatation of colonic loops, moreover.

\section{References}

1. van der Wal JB, Jeekel J. Biology of the peritoneum in normal homeostasis and after surgical trauma. Colorectal Dis. 2007;9:9-13.

2. Boland GM, Weigel RJ. Formation and prevention of postoperative abdominal adhesions. J Surg Res. 2006;132:3-12.

3. Chung DR, Chitnis T, Panzo RJ, Kasper DL, Sayegh MH, Tzianabos $\mathrm{AO} . \mathrm{CD}^{+} \mathrm{T}$ cells regulate surgical and postinfectious adhesion formation. J Exp Med. 2002;195:1471-8.

4. Kosaka H, Yoshimoto T, Yoshimoto T, Fujimoto J, Nakanishi $\mathrm{K}$. Interferon- $\gamma$ is a therapeutic target molecule for prevention of postoperative adhesion formation. Nat Med. 2008;14:437-41.

5. Ivarsson ML, Holmdahl L, Franzén G, Risberg B. Cost of bowel obstruction resulting from adhesions. Eur J Surg. 1997;163:679-84.

6. van Goor H. Consequences and complications of peritoneal adhesions. Colorectal Dis. 2007;9:25-34.

7. Lopes JB, Dallan LAO, Moreira FP, Carreiro MC, Luana F, Rodrigues B, Mendes PC, Stolf NAG. New quantitative variables to measure postoperative pericardial adhesions. Useful tools in experimental research. Acta Cir Bras. 2009;24:82-6.

8. Tingstedt B, Isaksson J, Anderson R. Long-term follow-up and cost analysis following surgery for small bowel obstruction caused by intra-abdominal adhesions. Br J Surg. 2007;94:743-8.

9. Kim S, Lee S, Greene AK, Arsenault DA, Le H, Meisel J, Novak K, Flynn E, Heymach JV, Puder M. Inhibition of intra-abdominal adhesion formation with the angiogenesis inhibitor sunitinib. J Surg Res. 2008;149:115-9.
10. Lang RA, Grüntzig PM, Weisgerber C, Weis C, Odermatt EK, Kirschner MH. Polyvinyl alcohol gel prevents abdominal adhesion formation in a rabbit model. Fertil Steril. 2007;88(4 Suppl):1180-6.

11. Marcondes W, Herbella FAM, Matone J, Odashiro AN, Goldenberg A. Laparoscopic evaluation of abdominal adhesions with different prosthetic meshes in rabbits. J Soc Lap Surg. 2008;12:58-61.

12. Baroncello JB, Czeczko NG, Malafaia O, Ribas-Filho JM, Nassif PAN, Dietz AU. O uso de telas Parietex ${ }^{\circledR}$ e Surgisis ${ }^{\circledR}$ na correção de defeitos produzidos na parede abdominal de coelhos. Arq Gastroenterol. 2008;45:323-9.

13. Irkorucu O, Ferahköșe Z, Memiş L, Ekinci Ö, Akin M. Reduction of postsurgical adhesions in a rat model: a comparative study. Clinics. 2009;64:1423-8.

14. Taufiek KR, Wallwiener CW, Brochhausen C, Hierlemann H, Kraemer B, Wallwiener M. Adhesion prophylaxis using a copolymer with rationally designed material properties. Surgery. 2009;145:196201.

15. van Ruber O, Mahler CW, Boer KR. Randomized trial strategy in patients with severe peritonitis: a comparison of on-demand vs planned relaparotomy. J Am Med Assoc. 2007;298:865-72.

16. Bicalho PRR, Lima LB, Alvarenga DG, Duval AI, Nunes TA, Reis FA. Clinical and histological responses to laparoscopically-induced peritonitis in rats. Acta Cir Bras. 2008;23:456-61.

17. Risberg B. Adhesions: preventive strategies. Eur J Surg. 1997;577:32-9.

18. Farquhar C, Vandekerckhove P, Watson A, Vail A, Wiseman D. Barrier agents for preventing adhesions after surgery for subfertility. Cochrane Database Syst Rev. 2000;(2):CD000475.

19. Sortini D, Feo CV, Maravegias K, Carcoforo P, Pozza E, Liboni A, Sortini A. Role of peritoneal lavage in adhesion formation and survival rate in rats: an experimental study. J Invest Surg. 2006;19:291-7.

20. Maleckas A, Daubaras V, Vaitkus V, Aniuliené A, Diržinauskas E, Rakauskas M. Pundzius J. Increased postoperative peritoneal adhesion formation after the treatment of experimental peritonitis with chlorhexidine. Langenbeck's Arch Surg. 2004;389:256-60.

\section{Correspondence:}

Ivana Duval Araújo

Departamento de Cirurgia, Faculdade de Medicina, UFMG

Avenida Professor Alfredo Balena, 190

30130-100 Belo Horizonte-MG Brasil

idaraujo@medicina.ufmg.br

Received: May 10, 2013

Review: July 11, 2013

Accepted: Aug 14, 2013

Conflict of intertest: none

Financial source: PRPq, FAPEMIG

${ }^{1}$ Research performed at Laboratory of Experimental Surgery, Department of Surgery, Medical School, Federal University of Minas Gerais (UFMG), Belo Horizonte-MG, Brazil. Part of Master degree thesis, Postgraduate Program in Surgery. Tutor: Profa. Ivana Duval Araújo. 